\title{
Low-emission pathways in 11 major economies: comparison of cost-optimal pathways and Paris climate proposals
}

\author{
Heleen L. van Soest ${ }^{1} \cdot$ Lara Aleluia Reis ${ }^{2,3}$ - Laurent Drouet ${ }^{2,3}$ • \\ Detlef P. van Vuuren ${ }^{1,4}$ • Michel G. J. den Elzen ${ }^{1}$ - Massimo Tavoni ${ }^{2,3,5}$. \\ Keigo Akimoto ${ }^{6}$ - Katherine V. Calvin ${ }^{7}$ - Panagiotis Fragkos ${ }^{8}$. \\ Alban Kitous ${ }^{9} \cdot$ Gunnar Luderer $^{10} \cdot$ Keywan Riahi $^{11}$
}

Received: 13 September 2016 / Accepted: 31 March 2017 /Published online: 21 April 2017

(C) Springer Science+Business Media Dordrecht 2017

\begin{abstract}
In order to evaluate the effectiveness of climate policy, it is important to understand emission trends and policies at the national level. The 2015 Paris Agreement includes (Intended) Nationally Determined Contributions, so-called (I)NDCs, outlining the contribution of different Parties to the overall target of the agreement to limit global mean temperature increase to well below $2{ }^{\circ} \mathrm{C}$. Here, we assess emission trajectories and the energy system transition of 11 major economies (in the remainder: countries) projected by integrated assessment models (IAMs) for baseline and cost-optimal $450 \mathrm{ppm} \mathrm{CO}_{2}$ eq mitigation scenarios and compare the results with the (I)NDCs. Limiting global temperature increase to below $2{ }^{\circ} \mathrm{C}$ implies a substantial reduction of the estimated available carbon budget for each country. The national carbon budgets between 2010 and 2100 showed reductions between the baseline and the $2{ }^{\circ} \mathrm{C}$ consistent mitigation
\end{abstract}

Electronic supplementary material The online version of this article (doi:10.1007/s10584-017-1964-6) contains supplementary material, which is available to authorized users.

Heleen L. van Soest

Heleen.vanSoest@pbl.nl

1 PBL Netherlands Environmental Assessment Agency, P.O. Box 30314, 2500 GH The Hague, The Netherlands

2 Fondazione Eni Enrico Mattei (FEEM), Corso Magenta 63, Milan, Italy

3 Centro Euro-Mediterraneo sui Cambiamenti Climatici, Corso Magenta, 63, 20123 Milan, Italy

4 Copernicus Institute of Sustainable Development, Utrecht University, P.O. Box 80.115, 3508 TC Utrecht, The Netherlands

5 Politecnico di Milano, Department of Management and Economics, Piazza Leonardo da Vinci, 32, 20133 Milan, Italy

6 Research Institute of Innovative Technology for the Earth, 9-2, Kizugawadai, Kizugawa-Shi, Kyoto 619-0292, Japan 
scenario ranging from 52\% in South Korea to $95 \%$ in Brazil. While in the baseline scenario, the share of low-carbon primary energy sources is projected to remain around 15\% (with Brazil being a notable exception, reaching $30 \%$ ); in the mitigation scenarios, the share of low-carbon energy is projected to increase to over $50 \%$ in 2050 in nearly all countries, with the EU, Japan and Canada reaching the largest shares. Comparison with the (I)NDCs shows that in Brazil, Canada, the EU, Mexico (conditional target), South Korea and the USA, the emission reduction targets of the NDCs are closer to the mitigation requirement of the $2{ }^{\circ} \mathrm{C}$ scenario; in other countries, however, there is still a large gap. The national detail of the indicators adds to the literature on low-carbon emission pathways, assists the assessment of the Paris Agreement and provides support to national policymakers to identify focus areas for climate policy in the coming years.

\section{Introduction}

At the twenty-first Conference of Parties in Paris in December 2015, governments worldwide agreed that the increase of global mean temperature should be limited to well below $2{ }^{\circ} \mathrm{C}$ with respect to pre-industrial levels (UNFCCC 2015) and possibly even below $1.5^{\circ} \mathrm{C}$. The IPCC Fifth Assessment Report (AR5) indicated that without new climate policies, global mean temperature will increase by approximately $3-4^{\circ} \mathrm{C}$ by 2100 (Clarke et al. 2014). Urgent and far-reaching emission reductions are required in all regions to remain well below $2{ }^{\circ} \mathrm{C}$ (Tavoni et al. 2014). In this context, 189 Parties to the United Nations Framework Convention on Climate Change (UNFCCC) submitted their Intended Nationally Determined Contributions (INDCs) to the Paris Agreement. When a country ratifies the Paris Agreement, its INDC becomes an NDC (127 Parties have done so at the time of writing).

Integrated assessment models (IAMs) are a useful tool to assess the implications of these (I)NDCs for the energy system and for regional and global emissions. IAM scenarios for international climate policy have been developed in projects such as AMPERE (Kriegler et al. 2014a), LIMITS (Kriegler et al. 2014b; Riahi et al. 2015; Tavoni et al. 2014), RoSE (Luderer et al. 2016) and the Energy Modelling Forum (Kriegler et al. 2014c). These scenarios cover emission trajectories without new climate policies, estimates of current policies and different variants of scenarios aiming at a $2{ }^{\circ} \mathrm{C}$ target. These scenarios, which vary on probability of achieving the target, technology assumptions and the timing of climate policy, have played a key role in the analysis for the most recent IPCC report (Clarke et al. 2014).

The design of the Paris Agreement, based on a pledge-and-review process, calls for national assessments due to the bottom-up nature of the (I)NDCs and because Parties are invited to submit 'long-term low greenhouse gas emission development strategies' (UNFCCC 2015). At

7 Pacific Northwest National Laboratory's Joint Global Change Research Institute, 5825 University Research Court, Suite 3500, College Park, MD 20740, USA

8 Department of Electrical and Computer Engineering, National Technical University of Athens, 9, Iroon Politechniou Street, 15773 Zografou Campus, Athens, Greece

9 European Commission, DG Joint Research Centre (JRC), Institute for Prospective Technological Studies (IPTS), Unit J1-Economics of Climate Change, Energy and Transport, Edificio Expo, C/ Inca Garcilaso, 3, 41092 Sevilla, Spain

10 Potsdam Institute for Climate Impact Research (PIK), P.O. Box 6012 03, 14412 Potsdam, Germany

11 International Institute for Applied Systems Analysis, Schlossplatz 1, 2361 Laxenburg, Austria 
the same time, the effectiveness of climate policy needs to be analysed at the global level. The assessment of regional outcomes of global IAM frameworks, as done in this paper, provides an opportunity to bridge both levels. The IAM models with which the scenarios were developed typically include regions, ranging from 10 to 30. Only a few studies have focussed on these national results (e.g. Herreras Martínez et al. 2015; Tavoni et al. 2014; Van Sluisveld et al. 2013; Veysey et al. 2016). We built on this work and analysed the national results for 11 major economies, including countries that have not been studied in detail in similar assessments. While national scenarios can also contribute to informing decarbonisation pathways (e.g. Bataille et al. 2016), we restrict this analysis to results of global IAMs to maximise comparability of results across regions.

So far, most of the analysis has been focused on the global results of these scenarios. Yet, climate policy, although also driven by international negotiations and a global goal, is formulated at the national level. The main objective of this study was to focus on the regional emission trajectories (Sects. 3.2 and 3.3) and the national energy system changes (Sect. 3.4). In light of the Paris Agreement, the regional baseline and cost-optimal $2{ }^{\circ} \mathrm{C}$ scenario results were compared to the (I)NDCs (UNFCCC 2016). We present various policy relevant indicators (such as national carbon budgets; Sect. 3.1) under baseline projections and pathways consistent with a $2{ }^{\circ} \mathrm{C}$ target. This analysis helps positioning countries regarding cost-effective lowemission pathways, promoted by the Paris Agreement. It could further inform the global stocktake under the Paris Agreement, starting with a 'facilitative dialogue' in 2018 and official stocktake in 2023. The focus of the analysis is on national results and not on model comparison (for the latter, see for instance Kriegler et al. 2014b; Riahi et al. 2015; Tavoni et al. 2014).

\section{Methods}

The analysis presented here builds upon the Modelling and Informing Low-Emission Strategies (MILES) project. MILES is an international cooperation project between 19 international research teams. ${ }^{1}$ In the analysis, the results from IAM scenarios developed in previous studies were compared for 11 major economies. These studies included AMPERE, LIMITS and EMF27 (Kriegler et al. 2014a,b; Riahi et al. 2015; Tavoni et al. 2014; Kriegler et al. 2014c), with each of these studies including several models. The models covered by the studies are DNE21+, GCAM, GEM-E3, IMAGE, MESSAGE, POLES, REMIND and WITCH. In addition, some new GCAM scenarios were included in the MILES database (Spencer and Pierfederici 2015). From each study, we selected the baseline scenarios and the cost-optimal $450 \mathrm{ppm} \mathrm{CO}_{2}$ eq scenarios, as described in Table 1. The main reason is that these scenario categories were the most clearly defined across the different studies. Cost-optimal scenarios are further often used as benchmark for policy analyses (e.g. Clarke et al. 2014). The target of $450 \mathrm{ppm} \mathrm{CO}_{2}$ eq is considered equivalent to limiting temperature increase below $2^{\circ} \mathrm{C}$ by 2100 with a $66 \%$ chance.

The 11 major economies ${ }^{2}$ studied were Brazil, Canada, China, EU, India, Japan, Mexico, Russia, South Korea, Turkey and USA. These countries were responsible for $70 \%$ of global

\footnotetext{
${ }^{1}$ ERI, RUC, TU, TERI, IIM, COPPE, PNNL, NIES, RITE, ICCS, IIASA, PIK, PBL, CMCC, CLU, IDDRI, CCROM, CRE, INECC

${ }^{2}$ In the remainder: countries, while there is one exception (EU).
} 
Table 1 Scenario categories used in this study

\begin{tabular}{|c|c|}
\hline Category & Description \\
\hline Baseline & $\begin{array}{l}\text { Scenarios that assume no new climate policies are put into place from } 2005 \\
\text { onwards, and the data is calibrated to the historical period (to 2010). This } \\
\text { scenario category thus acts as a counterfactual scenario providing a consistent } \\
\text { reference across all regions for showing the impact of climate policies. }\end{array}$ \\
\hline $\begin{array}{l}\text { Cost-optimal } 450 \mathrm{ppm} \mathrm{CO}_{2} \\
\text { equivalent }\end{array}$ & $\begin{array}{l}\text { Idealised scenarios that project global greenhouse gas concentrations below } \\
450 \mathrm{ppm} \mathrm{CO}_{2} \text { equivalent by } 2100 \text {. A universal global carbon tax is } \\
\text { implemented immediately from } 2010 \text { to } 2012 \text { onwards, in order to reach the } \\
450 \mathrm{ppm} \mathrm{CO}_{2} \text { eq concentration level, resulting in the lowest costs (within the } \\
\text { model). Therefore, the term 'optimal' represents the solution that maximises the } \\
\text { regional welfare and attains the carbon budget constraint. Treatment of climate } \\
\text { policy revenues (e.g. recycling of carbon tax revenues) was left to the } \\
\text { modeller's decision, considering some guidelines. The target of } 450 \mathrm{ppm} \mathrm{CO}_{2} \\
\text { eq is considered equivalent to limiting temperature increase below } 2{ }^{\circ} \mathrm{C} \text { by } \\
2100 \text { with a } 66 \% \text { chance. }\end{array}$ \\
\hline
\end{tabular}

emissions in 2012 (EC-JRC, PBL 2014) and are largely covered by the models in the MILES database. Not all models include all of these countries in their spatial aggregation, implying that for many countries, the results were based on a lower number of models.

In the models, the contribution of each country in global reductions is determined by equal marginal abatement costs across all countries driven by a uniform global price. Therefore, emissions are reduced where it is most cost optimal according to the model's marginal abatement costs. This implies that the costs of achieving these reductions are covered by the countries where the measures are implemented. It is still possible to share these costs on the basis of equity and fairness criteria. For example, countries can be compensated for their mitigation by means of direct transfers or by establishing an international carbon trading system (e.g. Fujimori et al. 2016) with emission rights allocated on the basis of equity principles. This is, however, not further explored in this article. In addition to the cost optimisation at the regional level, DNE21+, MESSAGE, REMIND and WITCH are perfect foresight models, that is, they optimise over time. The other models are recursive-dynamic simulation models (except for GEM-E3, which is a recursive-dynamic optimisation model). Some of these, such as the IMAGE model, still minimise costs over time using iterative procedures or by prescribing a carbon price trajectory. The $450 \mathrm{ppm} \mathrm{CO}_{2}$ eq scenarios considered here are assumed to start global cost-optimal mitigation in 2010-2012, which is not realistic given the current international climate policy landscape and historical trends in greenhouse gas emissions. However, these idealised scenarios are a useful modelling convention and provide a sense of the effort required to meet the $2{ }^{\circ} \mathrm{C}$ target.

The national model results were compared with the possible emission reductions resulting from implementing the (I)NDCs. The emission and peak year projections resulting from full implementation of the (I)NDCs were based on Den Elzen et al. (2016) and results from the WITCH model (Emmerling et al. 2016). Den Elzen et al. (2016) used official estimates for (I)NDC submissions, where available, supplemented with calculations based on documents submitted by countries to the UNFCCC, such as national communications and greenhouse gas inventories. The projections are in line with the median estimates presented in UNEP (2015). If no emission projection from these official studies could be calculated, i.e. for China and India, alternate sources were used. Emmerling et al. (2016) implemented the (I)NDC emission reductions aggregated to the native regions of $\mathrm{WITCH}$, using the Shared Socioeconomic 
Pathway 2 (SSP2) assumptions. For the comparison, three types of (I)NDC ranges were defined: range in the reduction targets as defined in the (I)NDCs (Russia, USA), range resulting from unconditional and conditional reduction targets (Mexico) and range resulting from various model studies (China, India). For China, the central estimate from Den Elzen et al. (2016) was used. The national results of the global models were reviewed by national experts.

\section{Results}

\subsection{Carbon budgets}

The scenario results could be used to calculate cumulative $\mathrm{CO}_{2}$ emissions over a given period, here 2010-2100. For the cost-optimal $450 \mathrm{ppm} \mathrm{CO}_{2}$ eq scenario, the global carbon budget is projected to be $1062 \mathrm{Gt} \mathrm{CO}_{2}$, within a range of $905-1307 \mathrm{Gt} \mathrm{CO}_{2}$. For the $2{ }^{\circ} \mathrm{C}$ scenario, the cumulative $\mathrm{CO}_{2}$ emissions per country can be interpreted as a national carbon budget consistent with achieving the climate target assuming cost-efficient implementation of the emission reductions across countries. Other budgets based on specific emission allocation schemes can also be designed. National carbon budgets can be used by national policy makers to evaluate their policies (see also Seneviratne et al. 2016; Tavoni and Van Vuuren 2015). On average, the national carbon budgets showed a reduction of approximately $79 \%$ between the baseline and cost-optimal $450 \mathrm{ppm} \mathrm{CO}_{2}$ eq scenario. The reduction in carbon budget between the baseline and the mitigation scenario was over $90 \%$ in Brazil, Mexico and Turkey, indicating these countries' relatively high mitigation potential according to the models (mostly related to land use in Brazil and to deployment of renewable energy, including biomass, and CCS in Mexico and Turkey; Fig. 1). After full implementation of the (I)NDCs, $471 \mathrm{Mt} \mathrm{CO}_{2}$ (conditional (I)NDCs) to $453 \mathrm{Mt} \mathrm{CO}_{2}$ (unconditional (I)NDCs) of the global carbon budget would be left to be nationally distributed until 2100 (similar to Rogelj et al. 2016).

\subsection{Greenhouse gas emissions}

Worldwide, greenhouse gas emissions are projected to increase strongly under the baseline scenarios, mostly driven by rapidly increasing emissions for the developing countries. Figure 2 shows the model average per capita $\mathrm{CO}_{2}$ emissions as a function of GDP per capita under the baseline and cost-optimal 450 ppm $\mathrm{CO}_{2}$ eq scenarios. Per capita emissions of Canada, the EU, Japan, South Korea and the USA are projected to remain stable or decline in the baseline, consistent with historical trends (Olivier et al. 2016). This is mainly driven by the assumptions on energy efficiency improvement in these countries. At the same time, driven by income growth, the per capita emissions of low-income to mid-income countries are projected to grow rapidly in the baseline. The picture drastically changes for the cost-optimal $450 \mathrm{ppm} \mathrm{CO}_{2}$ eq scenarios, in which nearly all countries, including the low-income to mid-income countries, are projected to reduce their per capita emissions. All countries are projected to have emissions below $5 \mathrm{t} \mathrm{CO}_{2}$ /capita by 2050, but with still generally higher per capita emissions in highincome countries than in low-income to mid-income countries.

Greenhouse gas emissions in 2030 would need to decrease significantly below the baseline in all countries to remain on a $2{ }^{\circ} \mathrm{C}$ pathway, as assumed in the cost-optimal $450 \mathrm{ppm} \mathrm{CO}_{2}$ eq scenario (Online Resource Fig. S.1). However, the cost-optimal 450 ppm $\mathrm{CO}_{2}$ eq scenario still 


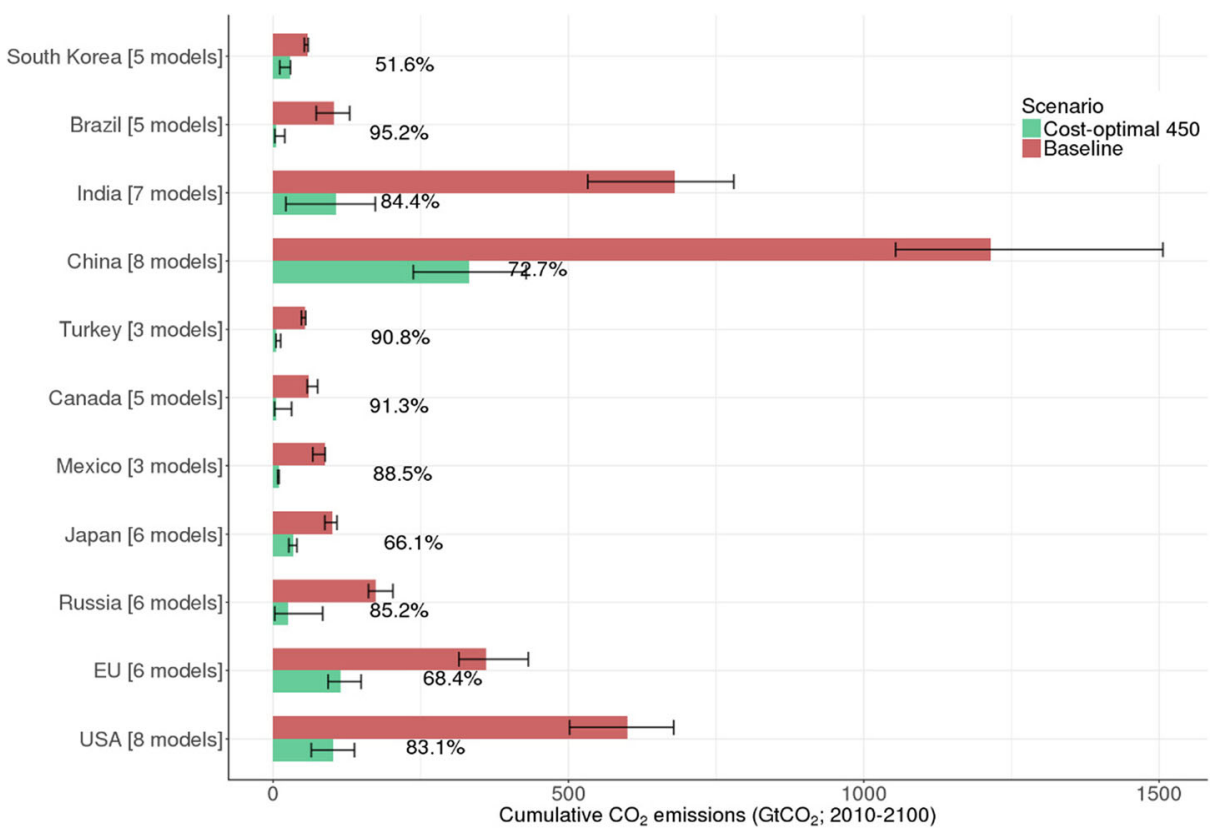

Fig. 1 Regional cumulative $\mathrm{CO}_{2}$ emissions $\left(\mathrm{Gt}^{\mathrm{CO}_{2}}\right)$ between 2010 and 2100, for cost-optimal $450 \mathrm{ppm} \mathrm{CO} \mathrm{CO}_{2}$ eq and baseline scenarios. Filled bars represent the median; error bars give the 10th to 90th percentile ranges across models. The number of models per country is indicated (number may differ per variable because not all variables are reported by all models), as well as the median reduction between baseline and cost-optimal $450 \mathrm{ppm} \mathrm{CO}_{2}$ eq (\%). The order of countries from top to bottom was determined by the baseline carbon budget in two groups, nonOECD and OECD90 countries (member of the OECD in 1990), and kept the same throughout the paper

allows an increase in emissions compared to 2010 levels for India. The differences in emission reductions across the countries reflect differences in mitigation potentials calculated by the models.
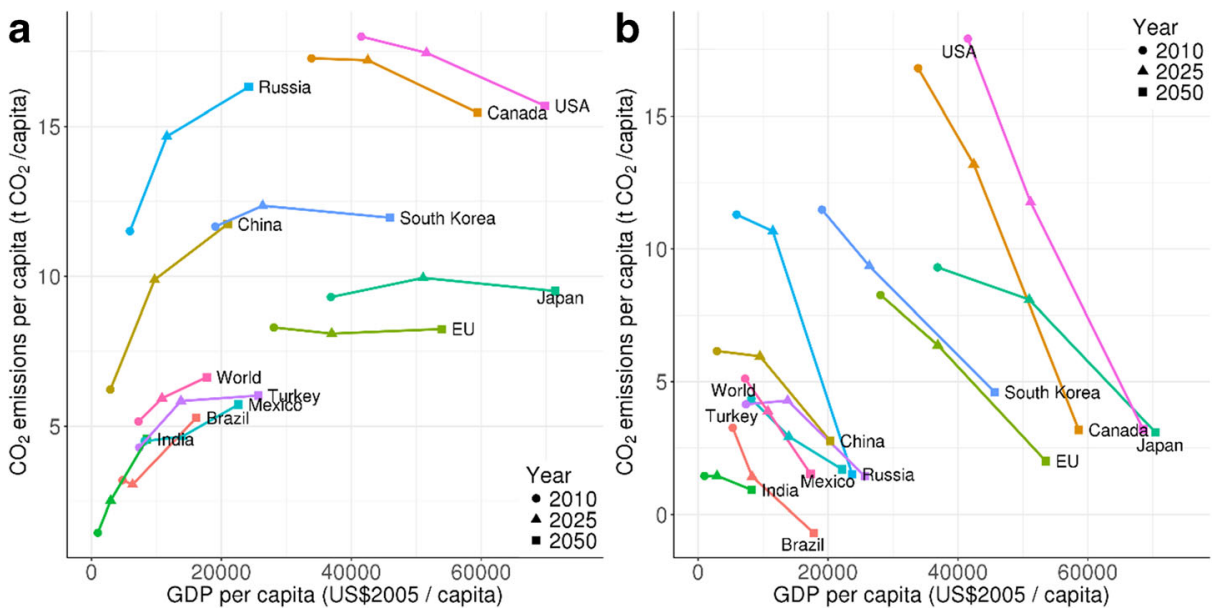

Fig. 2 Model average per capita $\mathrm{CO}_{2}$ emissions $\left(\mathrm{tCO}_{2} /\right.$ capita) versus GDP (in market exchange rate (MER)) per capita (US\$2005/capita) in 2010 (circles), 2025 (triangles) and 2050 (squares). a Baseline scenario. b Costoptimal $450 \mathrm{ppm} \mathrm{CO}_{2}$ eq scenario 
Comparing the (I)NDCs to these cost-optimal pathways informs about the level of ambition of the (I)NDCs, providing more national detail to analyses of the emission gap between global emission levels resulting from the (I)NDCs and global emission levels consistent with a likely chance of staying below $2{ }^{\circ} \mathrm{C}$ (e.g. Rogelj et al. 2016) (see also Online Resource Fig. S.2, showing what percentage of $450 \mathrm{ppm} \mathrm{CO}_{2}$ eq scenarios nationally fall above the estimated (I)NDC emissions in 2030). Full implementation of the NDCs of Canada, the EU, South Korea and the USA ${ }^{3}$ is projected to result in 2030 emissions close ${ }^{4}$ to the median model projections for the cost-optimal $450 \mathrm{ppm} \mathrm{CO}_{2}$ eq scenario (Fig. 3). For Mexico, only the conditional NDC target is close to the model projection. The NDCs of China and India are projected to result in emissions well above model projections for the cost-optimal $450 \mathrm{ppm} \mathrm{CO}_{2}$ eq scenario. However, the NDC projections for these countries are subject to many uncertainties, including uncertainties related to GDP growth rate projections and the implementation of policies announced in the NDCs. The NDC of Brazil is projected to result in emissions lower than the model projections for the cost-optimal $450 \mathrm{ppm} \mathrm{CO}_{2}$ eq scenario. The Japanese NDC is projected to be higher than the median model projection, but close to the lower end of the model range. The INDC emission target levels of Russia and Turkey are projected to be above the model range for cost-optimal $450 \mathrm{ppm} \mathrm{CO}_{2}$ eq, but these INDC levels are also above the projected baseline scenario levels. These countries are thus expected to overshoot their INDC targets with baseline developments.

Thus, all countries would need to realise larger emission reductions after 2030 to either get or remain on a globally cost-optimal pathway for $2{ }^{\circ} \mathrm{C}$ stabilisation. Table 2 presents the projected greenhouse gas emission reductions in 2050, relative to 2010, for the cost-optimal $450 \mathrm{ppm} \mathrm{CO}_{2}$ eq scenario. The median emission reduction is projected to be $46 \%$ globally but ranges from $78 \%$ in Canada to $8 \%$ in India.

The emission pathways provide a general sense of each country's contribution to GHG emissions, but each country realises emission reductions differently. Figure 4 shows the projected greenhouse gas emissions in 2050 in terms of $\mathrm{CO}_{2}$ emissions from fossil fuels and industry, $\mathrm{CO}_{2}$ emissions from land use and non- $\mathrm{CO}_{2}$ emissions. The emissions in each of these categories are projected to decline in the cost-optimal $450 \mathrm{ppm} \mathrm{CO}_{2}$ eq scenario with respect to the baseline projections, with land use emissions declining in relative importance towards 2050 and even turning negative in all countries except Indonesia and South Korea. Globally, $\mathrm{CO}_{2}$ emissions from fossil fuels and industry represent the majority of total emissions in both scenarios, but the relative contribution of non- $\mathrm{CO}_{2}$ emissions is projected to grow under the cost-optimal 450 ppm $\mathrm{CO}_{2}$ eq scenario. However, national differences can be observed. In China, for example, $\mathrm{CO}_{2}$ emissions from fossil fuels and industry are projected to remain the major contributor to total emissions, in line with the focus on $\mathrm{CO}_{2}$ in the Chinese NDC. In Brazil, in contrast, non- $\mathrm{CO}_{2}$ emissions represent the largest share of remaining emissions in the cost-optimal $450 \mathrm{ppm} \mathrm{CO}_{2}$ eq scenario, while land use emissions are projected to turn negative. This is in line with Brazil's NDC, which covers all greenhouse gases and includes measures to reduce emissions from land use change.

\footnotetext{
${ }^{3}$ The USA's NDC target for 2025 was extrapolated to 2030 by assuming a linear pathway to the national longterm target ( $83 \%$ reduction below 2005 levels by 2050).

${ }^{4}$ Here defined as less than 10 percentage point difference between the (I)NDC and cost-optimal 450 ppm CO $\mathrm{CO}_{2}$ eq scenario projections (Fig. 3).
} 


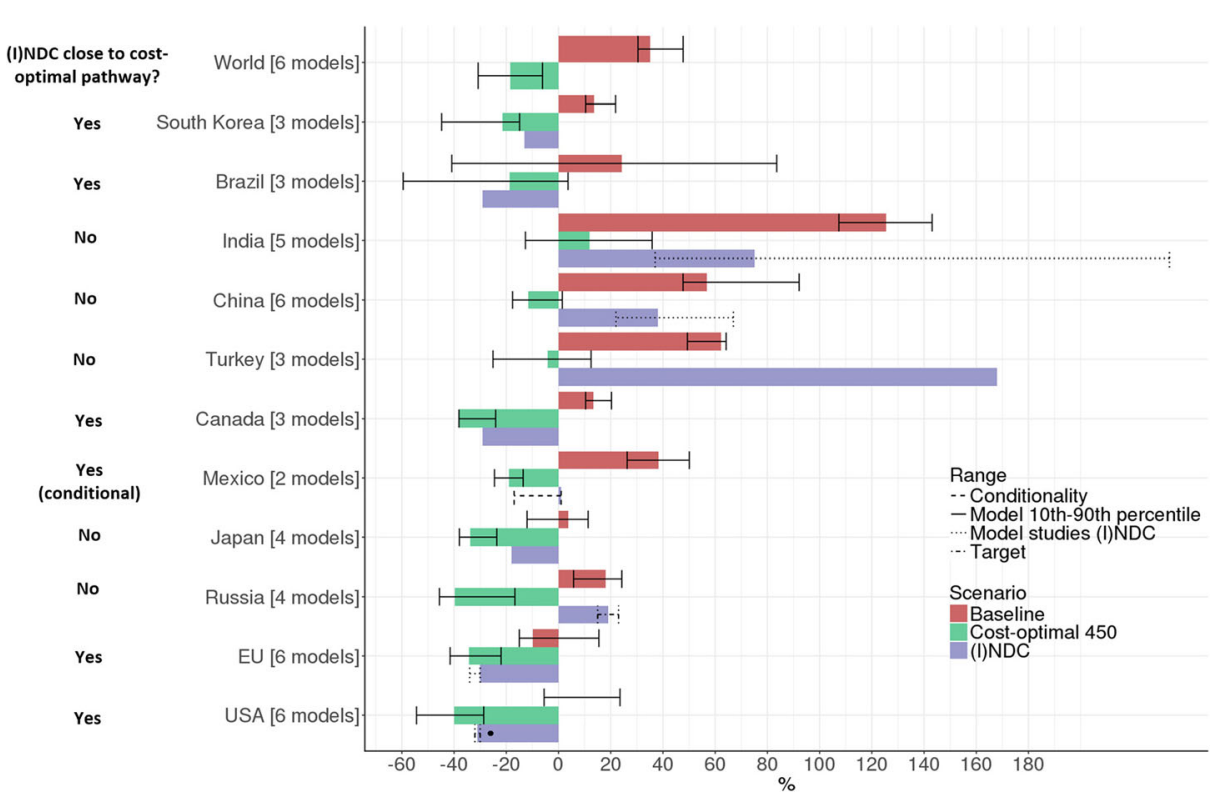

Fig. 3 Kyoto gas emissions in 2030 projected by models for baseline and cost-optimal 450 ppm $\mathrm{CO}_{2}$ eq scenarios, compared to (I)NDCs. Total emissions are shown with respect to $2010(\%$, with positive numbers indicating emission increase). The number of models per country is indicated. Filled bars for baseline and costoptimal 450 ppm $\mathrm{CO}_{2}$ eq show the median value across models; error bars show the 10th to 90th percentile range of the model results ('Model 10th-90th percentile'). For regions covered by less than three models, the range (minimum-maximum) is shown. Filled bars for (I)NDC show the central estimate from Den Elzen et al. (2016), error bars the range. (I)NDC ranges are of three types: range in the reduction target mentioned in the (I)NDCs themselves ('Target'; Russia, USA), range resulting from unconditional and conditional targets ('Conditionality'; Mexico; filled bar shows the unconditional target; error bar shows the effect of moving to the conditional target) and range resulting from various model studies analysed in UNEP (2015) ('Model Studies (I)NDC'; India, China). For the USA, the (I)NDC range consists of both 'Target' (error bar, based on den Elzen et al. 2016) and 'Model Studies (I)NDC' (filled circle, based on Emmerling et al. 2016). The column on the left shows whether a country's (I)NDC is close to the cost-optimal $450 \mathrm{ppm} \mathrm{CO}_{2}$ eq projection, where 'close' is defined as less than 10 percentage point difference

\subsection{Peak years}

Full implementation of (I)NDC targets is projected to result in emission trajectories with different emission peak years and peak emission levels across countries, as calculated in Den Elzen et al. (2016). The same holds for cost-optimal mitigation scenarios. Figure 5 presents peak years in greenhouse gas emissions per country. Under the cost-optimal $450 \mathrm{ppm} \mathrm{CO}_{2}$ eq scenario, most countries' greenhouse gas emissions are projected to peak before 2025, while India is projected to peak shortly after 2025. Canada, EU, Japan, Russia, South Korea and USA already peaked before 2015. $\mathrm{CO}_{2}$ emissions are generally projected to peak earlier (Online Resource Fig. S.3). Three groups of countries can be distinguished in comparing the modelled greenhouse gas peak years under the cost-optimal $450 \mathrm{ppm} \mathrm{CO}_{2}$ eq scenario to the projected (I)NDC peak years. First, countries with projected NDC peak years close to the model median for the cost-optimal $450 \mathrm{ppm} \mathrm{CO}_{2}$ eq scenario: Canada, India, Japan and USA. Second, countries with projected (I)NDC peak years earlier than or at the lower end of the model range: EU, Russia and South Korea. And third, countries with projected (I)NDC peak years later than or at the upper end of the model range: Brazil, China, Mexico and Turkey. 
Table 2 Greenhouse gas emissions (including from land use, land use change and forestry (LULUCF)) in 2050 relative to $2010(\%)$ for the cost-optimal $450 \mathrm{ppm} \mathrm{CO}_{2}$ eq scenario

\begin{tabular}{llcc}
\hline Region & 10th percentile & Median & 90th percentile \\
\hline Brazil [3 models] & -81.6 & -72.7 & -23.9 \\
Canada [3 models] & -86.6 & -77.6 & -43.9 \\
China [6 models] & -58.3 & -49.1 & -42.6 \\
EU [6 models] & -75.5 & -70.2 & -58.3 \\
India [5 models] & -54.9 & -7.8 & 11.8 \\
Japan [4 models] & -81.6 & -66.8 & -65.3 \\
Mexico [2 models] & -61.8 & & -31.9 \\
Russia [4 models] & -77.7 & -74.0 & -52.4 \\
South Korea [3 models] & -76.9 & -63.6 & -48.0 \\
Turkey [3 models] & -80.3 & -26.1 & -22.2 \\
USA [6 models] & -86.4 & -73.4 & -66.9 \\
World [6 models] & -58.1 & -46.2 & -42.8 \\
\hline
\end{tabular}

For regions covered by less than three models, only the range (minimum-maximum) is shown

\subsection{Energy mix}

Figure 6 shows that the share of low-carbon energy sources ${ }^{5}$ in energy supply is projected to increase substantially in the cost-optimal $450 \mathrm{ppm} \mathrm{CO}_{2}$ eq scenario, compared to the baseline scenario. In the baseline scenario, the contribution of low-carbon energy technology is projected to remain around $15 \%$, i.e. similar as today. In some countries, the baseline share in 2030 is projected to be lower than the 2010 share due to a phase-out of traditional biofuels. Still, in most countries, the share of low-carbon energy sources is projected to increase significantly. In the mitigation scenario, the share of low-carbon energy is scaled up further towards over $50 \%$ in 2050 (Online Resource Fig. S.4), with little differences between the countries (in 2030, differences between countries are still more pronounced because of different starting points). For developed countries, the mitigation scenario generally meant a substantial increase on 2010 levels. Some developing countries, such as Brazil and India, on the other hand, showed 2010 shares of low-carbon primary energy sources that were already close to the range reached in the mitigation scenario (over $25 \%$ of total primary energy supply in these cases).

\section{Discussion and conclusions}

The objectives of this study were to assess national emission trajectories and energy system changes for 11 major economies projected by global models and to compare the scenario results to the (I)NDCs. We derived policy-relevant indicators of these pathways in 11 countries, adding more national detail to the literature describing global model scenarios.

The global model-derived national carbon budgets add to the growing body of literature focusing on the relation between global climate change and regional impacts. For example, Seneviratne et al. (2016) noted that regional information would help political decision making and developing solutions. The indicators presented here and their comparison with (I)NDCs could thus help local policymakers identify focus areas for climate policy in the coming years, especially in relation to the UNFCCC global stocktaking set out in the Paris Agreement.

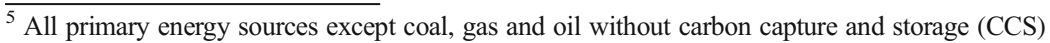



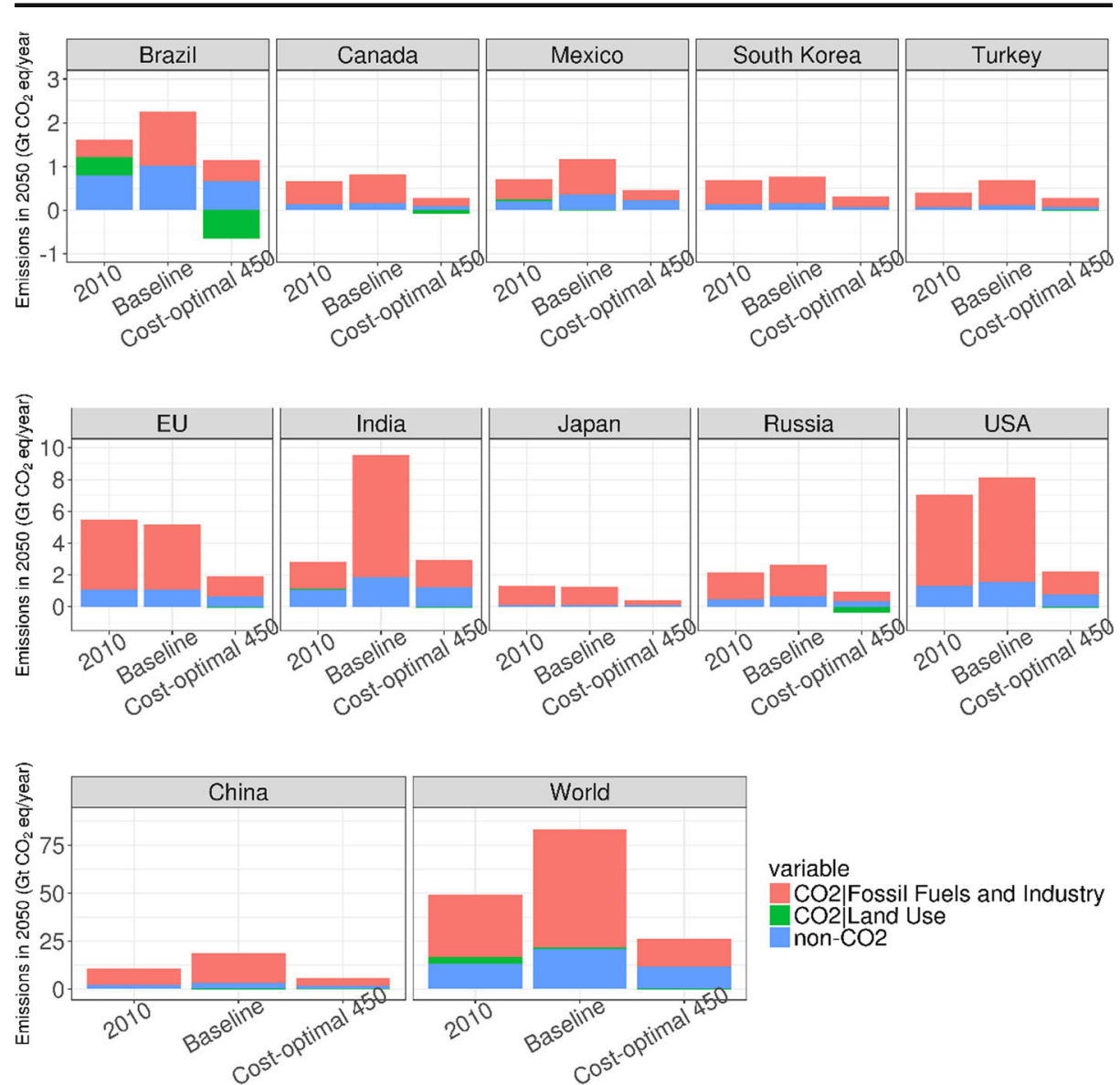

variable

$\mathrm{CO} 2$ Fossil Fuels and Industry

$\mathrm{CO} 2$ Land Use

non-CO2

Fig. $4 \mathrm{CO}_{2}$ emissions from energy supply and from land use and non- $\mathrm{CO}_{2}$ emissions in $2050\left(\mathrm{Gt}_{2} \mathrm{CO}_{2}\right.$ eq/year $)$ in baseline and cost-optimal $450 \mathrm{ppm} \mathrm{CO}_{2}$ eq scenarios (median across scenarios). Note the different $y$-axis scales across the three sets of panels

The ranges presented here are the result of several scenario runs from several models with different assumptions; thus, the national ranges of model results are interdependent, i.e. a pathway in a given country depends on the other countries' pathways. This means that the model range for a country might correspond only to a narrow range in all other countries. However, these national corridors remain indicative of what would be cost optimal in global mitigation scenarios.

The comparison of the results with (I)NDCs should be regarded as indicative given that the global model scenarios do not directly account for national policies and might not always thoroughly represent national energy systems. For example, the Fukushima accident makes it difficult for Japan to increase its nuclear power capacity, while most models still project a large increase in the share of nuclear energy. The Japanese NDC assumes a more modest share, leading to an emission gap between the NDC and the $450 \mathrm{ppm} \mathrm{CO}_{2}$ eq scenario. In addition, the definition of regions might be slightly different across models (especially for Europe). Fragkos et al. (2017) did a detailed model-based assessment of the EU's NDC and found that its targets are consistent with a cost-optimal distribution of physical emission reductions in a $2{ }^{\circ} \mathrm{C}$ pathway, similar to our findings. As the estimates for (I)NDC outcomes are still under development, this 


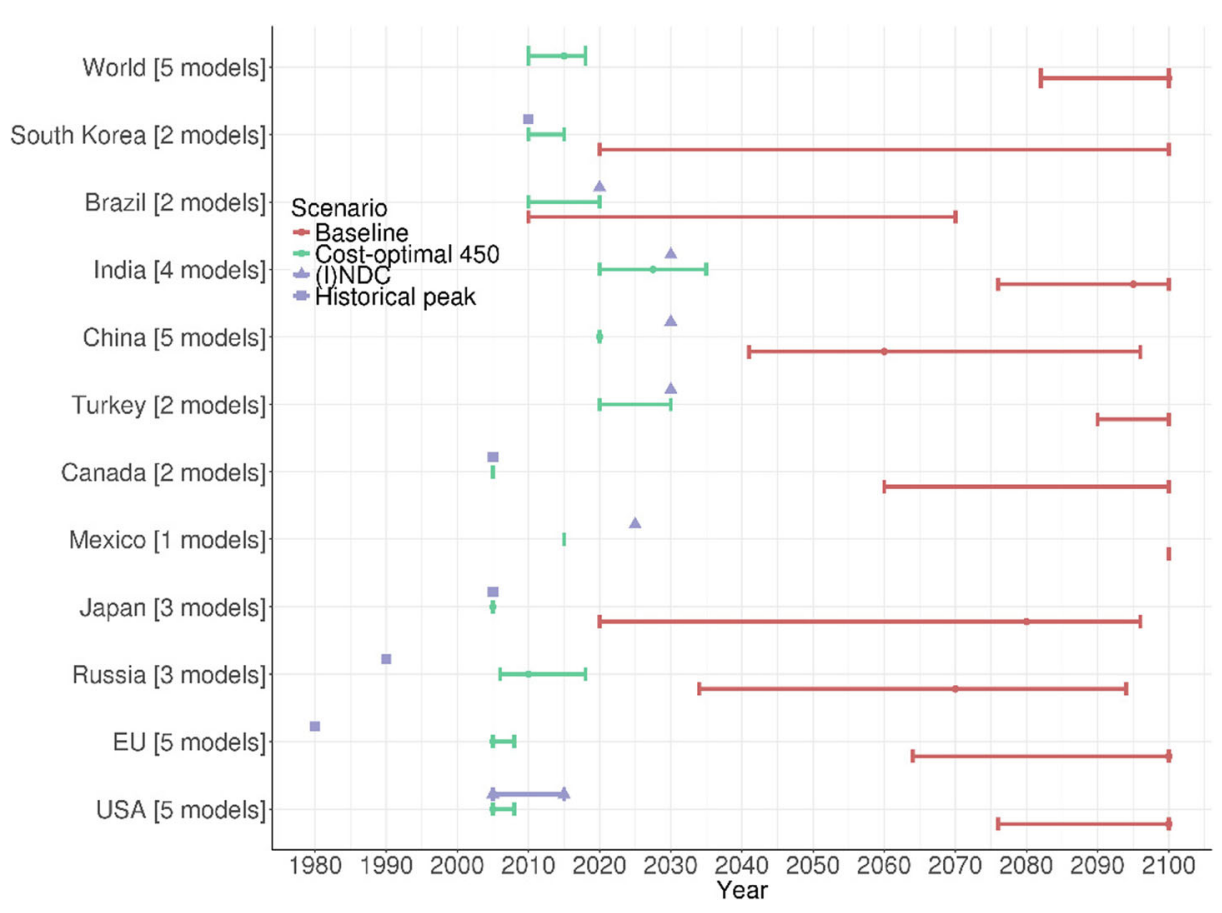

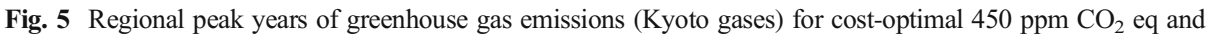
baseline scenarios. Dots give the median of the models; error bars give the 10th to 90th percentile ranges. The median results can be at the outer end of the range, for instance for OECD90. For regions covered by less than three models, only the range (minimum-maximum) is shown. Projected peak years under (I)NDCs are indicated by triangles (two estimates for USA, based on den Elzen et al. 2016 and Emmerling et al. 2016), while historical peak years are shown as squares. For most OECD90 countries, the cost-optimal 450 ppm $\mathrm{CO}_{2}$ eq scenario shows a peak year before 2015. For example for the EU, the models show 2005 as peak year under the cost-optimal $450 \mathrm{ppm} \mathrm{CO}_{2}$ eq scenario, because the start year for model analysis was 2005. As indicated for the EU's NDC, the actual peak year was around 1980. China's NDC peak year is for $\mathrm{CO}_{2}$ only

analysis is based on the information available to date. China, India and Mexico show large ranges in NDC emission projections. Finally, the fact that some projected (I)NDC emission reductions and peak years are not in line with the cost-optimal mitigation scenario should not be interpreted to mean that the $2{ }^{\circ} \mathrm{C}$ target will not be met. Alternate pathways (based on delay) might still be possible, although these could be considerably more expensive.

As indicated earlier, the scenarios in this study often used 2010-2012 as start year of comprehensive climate policies, which leads to lower emissions in subsequent years for the cost-optimal scenario. For policy scenarios, the differences are much smaller given the 2020 targets. Using a later starting year implies that the cost-optimal pathways would have somewhat higher emissions in the short run and somewhat higher costs and lower emissions in the long run. Given the trends in the 2010-2015 period, a later start year would especially influence results for China and India (in other countries, emission growth has been more modest), possibly reducing the difference between the (I)NDC and cost-optimal pathway to some extent (Online Resource Fig. S.5). Altogether, we expect that this might imply slightly different quantitative results but would not impact the overall conclusions.

For some countries, greenhouse gas emissions are projected to peak before the end of the century even in the baseline scenario, due to autonomous developments incorporated in this 


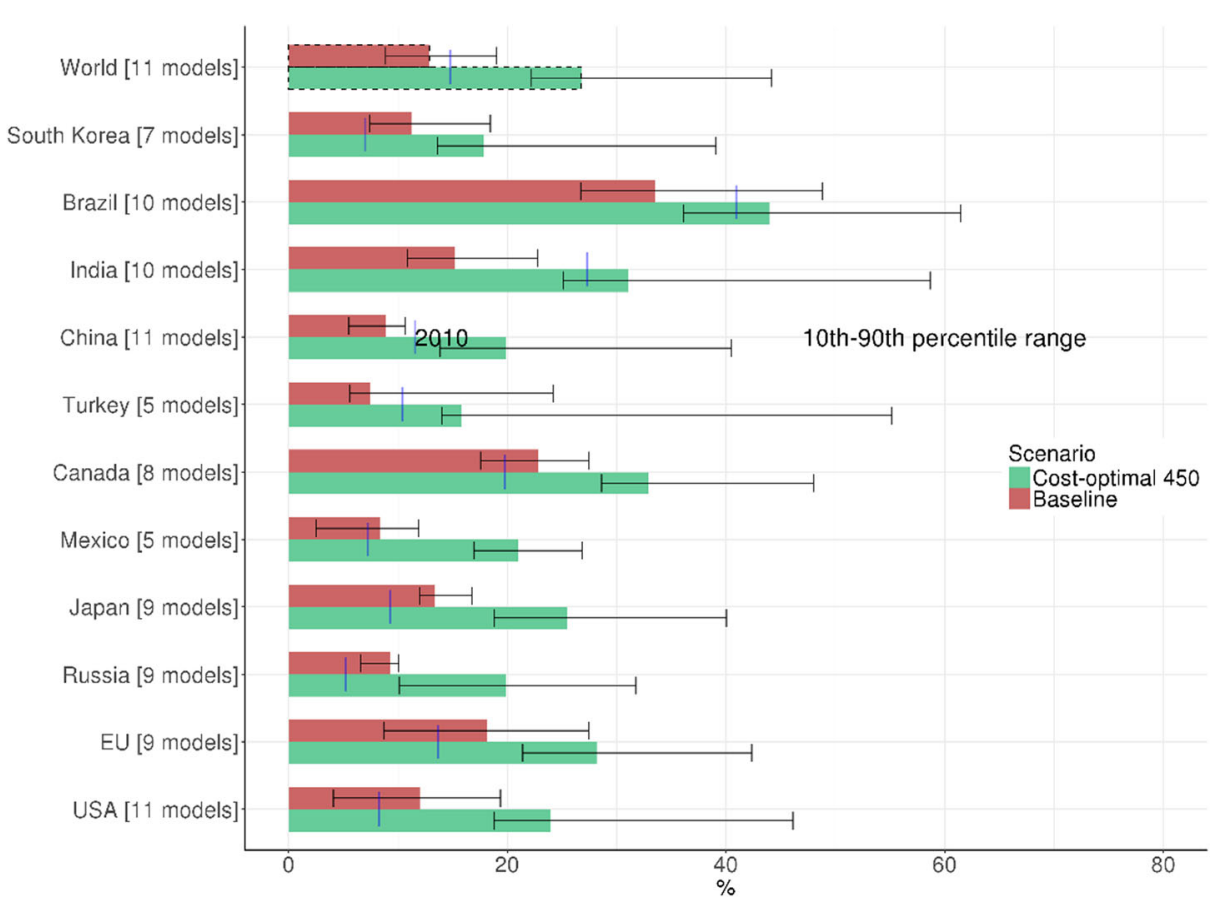

Fig. 6 Share (\%) of low-carbon primary energy sources (all energy sources except oil, coal and gas without carbon sequestration) in total primary energy supply in 2030, for cost-optimal $450 \mathrm{ppm} \mathrm{CO}_{2}$ eq and baseline scenarios. Filled bars represent the median; error bars give the 10th to 90th percentile ranges across models, and vertical blue lines give the 2010 shares (model median). Primary energy conversion for non-fossil fuels according to IEA statistics (physical energy content method)

scenario. The limited model coverage for some countries means that these results should be seen as being indicative of the projected emission trajectories and energy system changes. Especially land use emissions are a source of uncertainty in model projections.

The range in baseline greenhouse gas emission projections would affect relative abatement costs under the mitigation scenario and the (I)NDC. Uncertainty in emission reductions is especially large for Brazil, EU, Japan and USA, with model ranges crossing the zero reference line in the baseline. This not only reflects different assumptions on energy efficiency but also the uncertainty on the role of land use, land use change and forestry (LULUCF), most notably for Brazil. However, 2030 emissions for the cost-optimal $450 \mathrm{ppm} \mathrm{CO}_{2}$ eq scenario are robustly projected to be below the baseline, with the higher end of the cost-optimal $450 \mathrm{ppm} \mathrm{CO}_{2}$ eq scenario range below the lower end of the baseline range for all countries except the EU. This is even clearer when using per capita emissions. National differences in projected per capita emissions might evoke discussions on equity and fairness, with Brazil, India and Mexico projected to remain below the global average under the mitigation scenario. This points to the need for financial transfers in line with the principle of common but differentiated responsibilities to compensate developing countries and emerging economies with high mitigation potential. The model results presented here were derived from scenarios in which emission reductions were distributed across countries in a cost-optimal way, but actual costs could be distributed differently if aspects of equity are considered.

Given the discussion above and based on the results, the following main conclusions can be drawn. 


\section{Limiting global temperature increase to below $2^{\circ} \mathrm{C}$ implies a substantial reduction} of the cumulative $\mathrm{CO}_{2}$ emissions (carbon budget) between 2010 and 2100 for each country Our results confirm the general conclusion that major total and per capita emission reductions are needed in all countries to limit global warming to below $2{ }^{\circ} \mathrm{C}$. The national carbon budgets between 2010 and 2100 showed on average a $79 \%$ reduction between the baseline and the mitigation scenario, with the largest reductions projected for Brazil (95\%) and Canada (91\%) and the smallest for South Korea (52\%). After full implementation of the (I)NDCs, the world would be left with approximately $40 \%$ of the carbon budget for $2{ }^{\circ} \mathrm{C}$ for the rest of the century. Under the mitigation scenario, most countries' greenhouse gas emissions are projected to peak before 2025. Only Brazil, China, Mexico and Turkey have projected (I)NDC peak years later than the model peak years for the mitigation scenario.

In general, the (I)NDCs are insufficient to reach the mitigation level of the costoptimal $2^{\circ} \mathrm{C}$ scenarios However, the NDCs of Brazil, Canada, the EU, Mexico (conditional NDC), South Korea and the USA are projected to be relatively close. The NDCs of China and India are projected to result in emissions well above levels consistent with the cost-optimal $2{ }^{\circ} \mathrm{C}$ scenario. The NDC projections for these countries are surrounded with uncertainties, driven by uncertain GDP projections. The (I)NDCs of Japan, Russia and Turkey are projected to result in emissions higher than the model projections for the cost-optimal $450 \mathrm{ppm} \mathrm{CO}_{2}$ eq scenario. For Russia and Turkey, the emission projections of the INDCs are even above the baseline projections. At the global level, the sum of emission reductions projected to result from implementation of the (I)NDCs falls short of the reductions required in the cost-optimal $2{ }^{\circ} \mathrm{C}$ pathway. As shown here, however, the results differ significantly for the individual countries.

\section{All countries show increasing shares of low-carbon primary energy sources in the} mitigation scenario In the baseline scenario, the share of low-carbon primary energy sources is projected to remain around 15\% (except for Brazil 30\%). All countries showed increasing shares of low-carbon energy in the mitigation scenario, towards approximately $40 \%$ in some countries and over $50 \%$ in the other countries in 2050. Although these projected shares could not be compared directly to the (I)NDCs, they indicate that scaling up the share of low-carbon energy sources is needed for the (I)NDCs to follow a cost-optimal pathway to the $2{ }^{\circ} \mathrm{C}$ target.

Acknowledgements This study benefited from the financial support of the European Commission via the Modelling and Informing Low-Emission Strategies (MILES) project, financed by Directorate General Climate Action (DG CLIMA), under contract to DG CLIMA (No. 21.0104/2014/684427/SER/CLIMA.A.4), and the Linking Climate and Development Policies-Leveraging International Networks and Knowledge Sharing (CDLINKS) project, financed by the European Union's Horizon 2020 research and innovation programme under grant agreement no. 642147 (CD-LINKS). The work is largely based on published scenarios from integrated assessment modelling studies, collected for MILES. The results presented here are not automatically endorsed by MILES project partners. We thank Annemiek Admiraal (PBL) for providing (I)NDC data.

\section{References}

Bataille C, Waisman H, Colombier M et al (2016) The need for national deep decarbonization pathways for effective climate policy. Clim Pol 16:S7-S26

Clarke L, Jiang K, Akimoto K et al (2014) Assessing transformation pathways. In: Edenhofer O, Pichs-Madruga R, Sokona Y et al (eds) Climate Change 2014: Mitigation of Climate Change. Contribution of Working 
Group III to the Fifth Assessment Report of the Intergovernmental Panel on Climate Change. Cambridge University Press, Cambridge

EC-JRC, PBL (2014) Emission Database for Global Atmospheric Research (EDGAR) version 4.2FT2012 European Commission, Joint Research Centre (JRC) / PBL Netherlands Environmental Assessment Agency, http://edgar.jrc.ec.europa.eu/overview.php

den Elzen M, Admiraal A, Roelfsema M et al (2016) Contribution of the G20 economies to the global impact of the Paris Agreement climate proposals. Clim Chang 137:655-665

Emmerling J, Drouet L, Aleluia Reis L et al (2016) The WITCH 2016 model-documentation and implementation of the shared socioeconomic pathways, FEEM Nota di Lavoro 42.2016. FEEM, Venice

Fragkos P, Tasios N, Paroussos L et al (2017) Energy system impacts and policy implications of the European Intended Nationally Determined Contribution and low-carbon pathway to 2050. Energy Policy 100:216-226

Fujimori S, Kubota I, Dai H et al (2016) Will international emissions trading help achieve the objectives of the Paris Agreement? Environ Res Lett 11:104001

Herreras Martínez S, Koberle A, Rochedo P et al (2015) Possible energy futures for Brazil and Latin America in conservative and stringent mitigation pathways up to 2050. Technol Forecast Soc Chang 98:186-210

Kriegler E, Riahi K, Bauer N et al (2014a) Making or breaking climate targets: the AMPERE study on staged accession scenarios for climate policy. Technol Forecast Soc Chang 90:24-44

Kriegler E, Tavoni M, Aboumahboub T, et al. (2014b) What does the $2^{\circ} \mathrm{C}$ target imply for a global climate agreement in 2020?. The LIMITS study on Durban Platform scenarios. Climate Change Economics 4

Kriegler E, Weyant JP, Blanford GJ et al (2014c) The role of technology for achieving climate policy objectives: overview of the EMF 27 study on global technology and climate policy strategies. Clim Chang 123:353-367

Luderer G, Bertram C, Calvin K et al (2016) Implications of weak near-term climate policies on long-term mitigation pathways. Clim Chang 136:127-140

Olivier JGJ, Janssens-Maenhout G, Muntean M, Peters JAHW (2016) Trends in global CO2 emissions; 2016 Report. PBL Netherlands Environmental Assessment Agency / European Commission, Joint Research Centre, The Hague / Ispra

Riahi K, Kriegler E, Johnson N et al (2015) Locked into Copenhagen pledges - implications of short-term emission targets for the cost and feasibility of long-term climate goals. Technol Forecast Soc Chang 90:8-23

Rogelj J, den Elzen M, Höhne N et al (2016) Paris Agreement climate proposals need a boost to keep warming well below $2{ }^{\circ} \mathrm{C}$. Nature 534:631-639

Seneviratne SI, Donat MG, Pitman AJ et al (2016) Allowable CO2 emissions based on regional and impactrelated climate targets. Nature 529:477-483

Spencer T, Pierfederici R (eds) (2015) Beyond the numbers: understanding the transformation induced by INDCs. IDDRI - MILES Project Consortium, Paris, p 80

Tavoni M, Van Vuuren, DP (2015) Regional carbon budgets: do they matter for climate policy?, Nota di Lavoro 71.2015, Fondazione Eni Enrico Mattei, Milan

Tavoni M, Kriegler E, Riahi K et al (2014) Post-2020 climate agreements in the major economies assessed in the light of global models. Nat Clim Chang 5:119-126

UNEP (2015) The emissions gap report 2015. United Nations Environment Programme (UNEP), Nairobi

UNFCCC (2015) Paris Agreement. Decision 1/CP.17. http://unfccc.int/resource/docs/2015/cop21/eng/109r01. pdf, UNFCCC document FCCC/CP/2015/L.9/Rev.1

UNFCCC (2016) Aggregate effect of the intended nationally determined contributions: an update. Synthesis report by the secretariat. UNFCCC Secretariat, FCCC/CP/2016/2, http://unfccc.int/resource/docs/2016/cop22/eng/02.pdf

Van Sluisveld MAE, Gernaat DEHJ, Ashina S et al (2013) A multi-model analysis of post-2020 mitigation efforts of five major economies. Climate Chang Econ 04:1340012

Veysey J, Octaviano C, Calvin K et al (2016) Pathways to Mexico's climate change mitigation targets: a multimodel analysis. Energy Econ 56:587-599 